\title{
The Eastern Renewable Generation and Integration Study
}

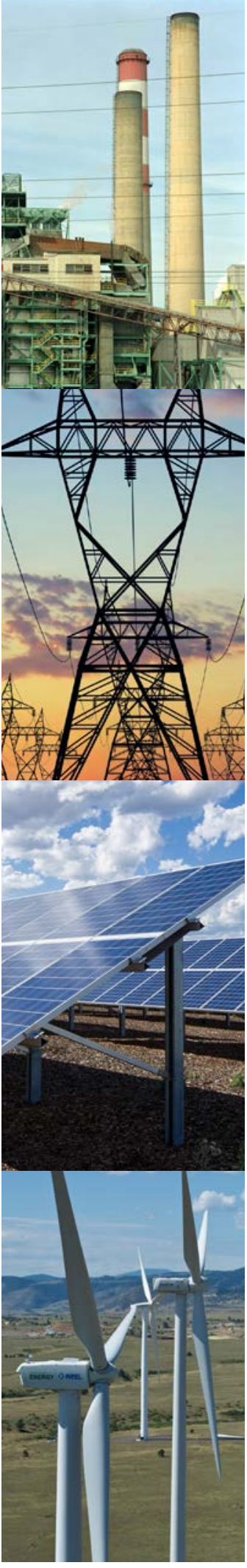

\section{About the Study}

State renewable portfolio standards are driving utilities across the United States to adopt higher penetrations of variable renewable energy. Although power systems have been designed to handle the variable nature of loads, the additional supply-side variability and uncertainty can pose new challenges for utilities and system operators. The Eastern Renewable Generation Integration Study (ERGIS) aims to answer critical questions about how the Eastern Interconnection (EI) could be operated under high penetrations of wind and solar generation.

ERGIS uses an advanced production-cost model (PLEXOS) with detailed subhourly data to study the impact of $30 \%$ wind and solar power penetration on ancillary services, interchange, and net load. ERGIS examines:

- How might power system operations be impacted by high levels of wind and solar power generation?

- Could the operational impacts differ based on policy decisions about regional versus national deployment strategies?

- How might the penetration levels of wind and solar resources drive other resource planning requirements?

- What are the potential impacts of high penetrations of wind and solar power on the cycling of thermal plants?

- How might some regional market structures be better suited to accommodate high penetrations of wind and solar power?

\section{Technical Review Committee}

To aid in the development of necessary data sets and analyze results as they become available, NREL worked with the U.S.
Department of Energy to bring together industry experts on a technical review committee (TRC). Representatives from utilities, regional transmission organizations/independent system operators, regulators, national laboratories, and equipment manufacturers comprise the TRC. In 2013, the TRC oversaw the development of several aspects of the project, including:

- Scenario development

- Thermal fleet expansion

- Transmission expansion

- Solar profile development

- Canadian system modeling

\section{Scenarios}

ERGIS considers four scenarios designed to evaluate the impact of different wind and solar power penetrations.

- National 30\% Scenario: Requires the U.S. portion of the EI to serve $30 \%$ of its annual load with wind and solar power, using the best wind and solar resources in the U.S. El

- Regional 30\% Scenario: Requires each individual region to serve $30 \%$ of its annual load with wind and solar power within its geographic boundaries, with the exception of SERC, which is allowed to import part of its requirement from the Southwest Power Pool

- State Renewable Portfolio Standards: Requires wind and solar generation to meet state Renewable Portfolio Standards for the model year 2025 as legislated in 2010

- Low Renewables: Holds wind and solar power penetration levels at the amount installed in the El in 2010.

\begin{tabular}{|c|c|c|c|c|c|c|c|c|c|c|}
\hline \multirow[b]{2}{*}{ Scenario } & \multicolumn{2}{|c|}{$\begin{array}{c}\text { Energy } \\
\text { Penetration (\%) }\end{array}$} & \multicolumn{2}{|c|}{$\begin{array}{l}\text { Solar Photovoltaic } \\
\text { Capacity (GW) }\end{array}$} & \multicolumn{2}{|c|}{ Wind Capacity (GW) } & \multicolumn{4}{|c|}{ Conventional Capacity (GW) } \\
\hline & Rooftop & Utility & Rooftop & Utility & Onshore & Offshore & Nuclear & Coal & $\begin{array}{l}\text { Combined } \\
\text { Cycle }\end{array}$ & $\begin{array}{c}\text { Combustion } \\
\text { Turbine \& } \\
\text { Boiler }\end{array}$ \\
\hline National $30 \%$ & 5 & 25 & 50 & 123 & 237 & 27 & 88 & 216 & 137 & 178 \\
\hline Regional 30\% & 10 & 20 & 96 & 123 & 168 & 46 & 88 & 212 & 133 & 173 \\
\hline $\begin{array}{l}\text { State Renewable } \\
\text { Portfolio Standards }\end{array}$ & 0.2 & 12 & 3 & 2 & 91 & 15 & 88 & 230 & 144 & 197 \\
\hline Low Renewables & 0 & 3 & 1 & 0 & 30 & 0 & 88 & 231 & 147 & 194 \\
\hline
\end{tabular}

Table 1. ERGIS Study Scenarios

* Ancillary services are wholesale market products needed to accomplish transmission service and

maintain reliability within and among control areas affected by transmission service.

(Source: Federal Energy Regulatory Commission, Order 888, April 24, 1996, www.ferc.gov/legal/maj-ord-reg/land-docs/rm95-8-00w.txt) 


\section{Understanding Impacts}

ERGIS uses state-of-the-art wind and solar data sets bundled with leading thermal fleet analysis to calculate production costs at an unprecedented fidelity. This study simulates operations at a 5 -minute resolution to determine how changes in wind and solar generation can alter the unit commitment and dispatch of the power system. A detailed representation of the existing transmission system, and future transmission expansions scenarios developed under the Eastern Interconnection Planning Collaborative, are used to model the transmission constraints that could impact the options for managing variability and uncertainty.

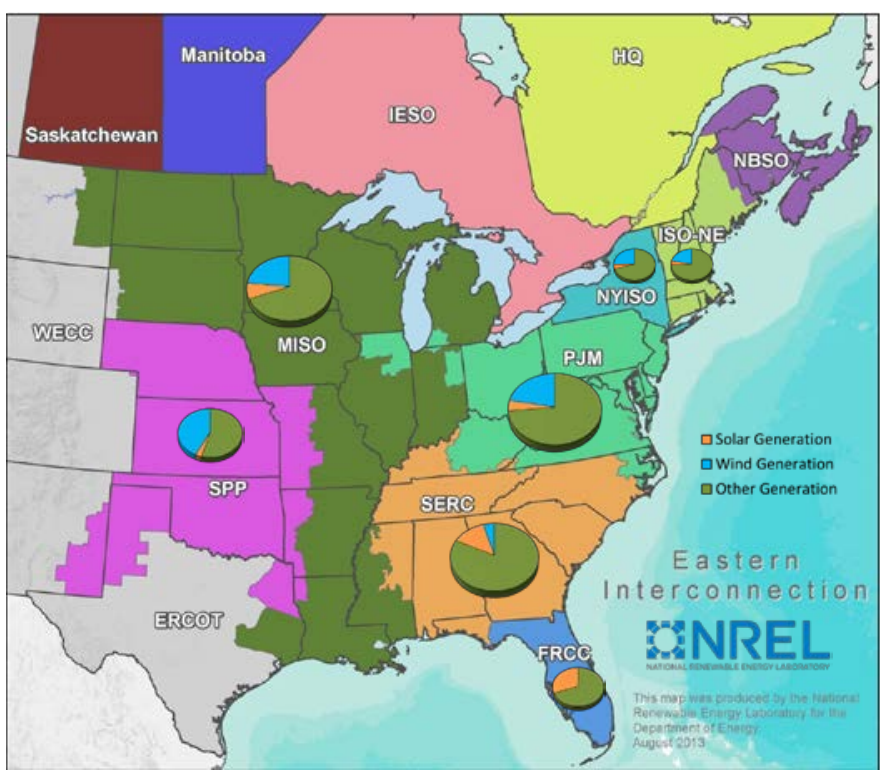

Figure 1. This map shows the assumed structure of the El in the study year. The pie chart slices indicate the relative amount of wind, solar, and other generation in each region, and the relative size of each pie chart indicates the amount of generation in each region for the Regional $30 \%$ Scenario.

\section{Mitigation Options}

ERGIS will evaluate modeling results to understand how production costs change under a variety of operation paradigms. This analysis will be used to determine the effectiveness of operational strategies that could be used to minimize the cost of integrating high penetrations of wind and solar power. Mitigation options of interest include:

- New or modified ancillary service products

- Increased sharing of ancillary services between regions

- Faster unit commitment and dispatch cycles

- More-frequent interchange scheduling

- Demand response
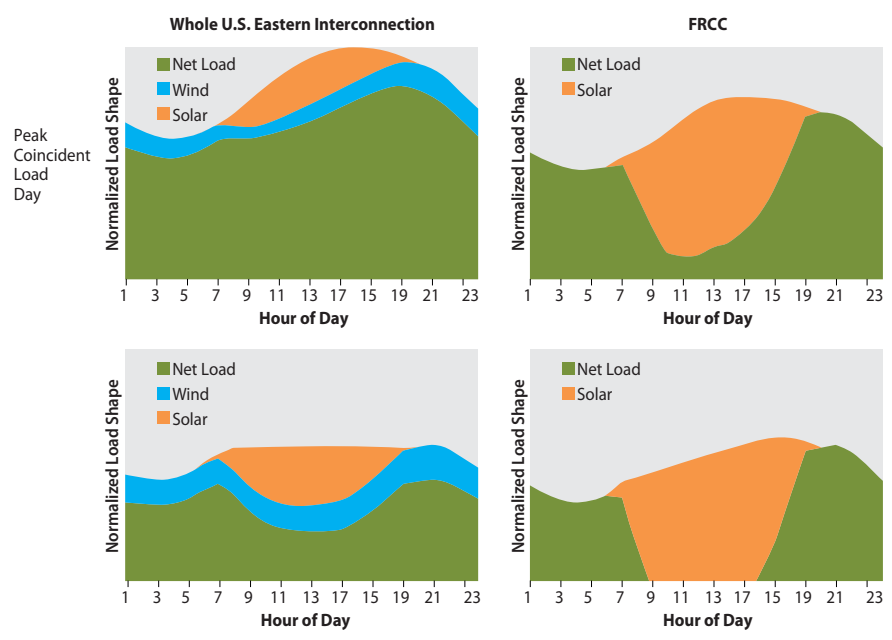

Figure 2. These graphs show normalized wind and solar generation and net load shapes for (left) the entire U.S. El and (right) Florida Reliability Coordinating Council for (top) the peak coincident load day and (bottom) a high solar generation day. Operating conventional generators to meet net load for the whole El seems reasonable, but it is likely that certain regions could have challenging issues that would require operational changes from current practices, as illustrated by the large ramps in the Florida Reliability Coordinating Council net load.

\section{Associated Publications}

D. Lew, G. Brinkman, E. Ibanez, B.-M. Hodge, M. Hummon, A. Florita, M. Heaney, G. Stark, J. King, N. Kumar, S. Lefton, D. Agan, G. Jordan, and S. Venkataraman. (2013). The Western Wind and Solar Integration Study Phase 2. NREL/TP-5500-55588. Golden, C0: National Renewable Energy Laboratory. Accessed October 2013: www.nrel.gov/docs/fy130sti/55588.pdf.

EnerNex Corporation. (2011). Eastern Wind Integration and Transmission Study. NREL/SR-5500-47078. Work performed by EnerNex Corporation, Knoxville, TN. Golden, CO: National Renewable Energy Laboratory. Accessed October 2013: www.nrel.gov/docs/fy110sti/47078.pdf.

GE Energy. (2010). The Western Wind and Solar Integration Study. NREL/SR-55047434. Work performed by GE Energy, Schenectady, NY. Golden, CO: National Renewable Energy Laboratory. Accessed September 2013: www.nrel.gov/docs/ fy10osti/47434.pdf.

\section{More Information}

Aaron Bloom, 720-402-2065, aaron.bloom@nrel.gov

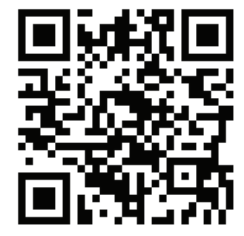

See our website at

www.nrel.gov/electricity/transmission/.
National Renewable Energy Laboratory

15013 Denver West Parkway, Golden, C0 80401 303-275-3000 • www.nrel.gov
NREL is a national laboratory of the U.S. Department of Energy, Office of Energy Efficiency and Renewable Energy, operated by the Alliance for Sustainable Energy, LLC. NREL/FS-5D00-60565 • February 2014 